\title{
Regulator of G Protein Signaling Transcript Expression in Human Neural Progenitor Differentiation: R7 Subfamily Regulation by DNA Methylation
}

\author{
Katie Tuggle Mourad W. Ali Hector Salazar Shelley B. Hooks \\ Department of Pharmaceutical and Biomedical Sciences, University of Georgia, \\ Athens, Ga., USA
}

\section{Key Words}

Regulator of $G$ protein signaling protein - Neural progenitor - Neuronal differentiation · DNA methyltransferase $\cdot$ Histone deacetylase $\cdot$ Epigenetics

\begin{abstract}
G protein-coupled receptors (GPCRs) and their ligands are critical regulators of neural progenitor differentiation, and GPCR signaling pathways are regulated by regulator of $G$ protein signaling (RGS) proteins. RGS protein expression is dynamically regulated, and we have recently described the epigenetic regulation of RGS transcript expression. Given the potential of RGS proteins to regulate GPCR signaling and the established role of epigenetic regulation in progenitor differentiation, we explored the impact of epigenetic regulation of RGS transcripts during in vitro differentiation of human neural progenitors. Here, we demonstrate robust upregulation of the RGS transcripts RGS4, RGS5, RGS6, RGS7, and RGS11 during neuronal differentiation, while DNA methyltransferase (DNMT) and histone deacetylase enzyme expression is suppressed during differentiation. Transcripts encoding R7 subfamily RGS proteins and the R7-binding partners R7BP and R9AP showed the greatest upregulation. Further, we showed that direct pharmacological inhibition of DNMT activity enhances expression of RGS2, RGS4, RGS5, RGS6, RGS7, RGS8, RGS9L, RGS10, and RGS14 as well as R7BP and R9AP transcripts in progenitors, consistent with regulation by DNMTs. Our results reveal marked upregulation of RGS expression during neuronal differentiation and suggest that decreased expression of DNMT enzymes during differentiation contributes to upregulation.


Tuggle et al.: Regulator of G Protein Signaling Transcript Expression in Human Neural Progenitor Differentiation: R7 Subfamily Regulation by DNA Methylation

\section{Introduction}

In development and stem cell differentiation, G protein-coupled receptors (GPCRs) are critical regulators of self-renewal and cell fate determination, particularly in neural lineages [1]. GPCRs comprise the largest family of cell-surface receptors in all eukaryotes [2]. The seven-transmembrane GPCR is an integral membrane protein that relays signaling cues from extracellular neurotransmitters, growth factors, and hormones to cellular machinery via activation of heterotrimeric $\mathrm{G}$ proteins. A large class of cellular proteins termed regulator of $\mathrm{G}$ protein signaling (RGS) proteins functions to reverse the activation of G proteins by GPCRs and their ligands [3]. When activated by an external ligand, the GPCR acts as a guanine-nucleotide exchange factor to cause exchange of GDP for GTP on the $\alpha$ subunit of the G protein. This allows the active $\mathrm{G} \alpha$ subunit and G $\beta \gamma$ dimer to dissociate and interact with effector proteins to induce various intracellular signaling cascades. The activity of $\mathrm{G} \alpha$ and $\mathrm{G} \beta \gamma$ is terminated by GTP hydrolysis which regenerates the inactive GDP-bound G protein [4]. RGS proteins accelerate and facilitate this GTP hydrolysis and thus deactivate G protein-mediated GPCR signals [5]. Further, multifunctional RGS proteins can target G proteins and receptors in distinct domains through scaffolding mechanisms, and thereby alter the relative strength of signaling from multiple pathways. Finally, GPCRs may signal through G protein-independent pathways such as arrestins, and RGS expression can alter the relative strength of these complementary pathways $(22006018,21699508)$. Thus, RGS proteins can regulate the strength, duration, and specificity of GPCR signaling pathways.

While GPCRs and G proteins have been extensively studied in neural differentiation [6], the ability of RGS proteins to regulate these pathways has been largely unexplored. Similarly, while others and we have reported dramatic changes in the expression of GPCRs during neuronal differentiation [1,7], little is known about the regulation of RGS expression during neuronal differentiation. Our recent studies have implicated epigenetic regulation of RGS transcript expression by histone deacetylation and DNA methylation [8], and epigenetic regulation of gene expression is a key determinant of stem cell differentiation [9]. Epigenetic regulation of gene expression encompasses multiple mechanisms that modify genomic DNA and histones - including DNA methylation, histone methylation, and histone acetylation - as well as expression of microRNAs. In the current study, we explored the changes in RGS transcript expression in neuronal differentiation of human neural progenitors, and examined the roles of DNA methyltransferase (DNMT) and histone deacetylase enzymes in regulating RGS expression. Our results suggest that decreased expression of DNMT enzymes may contribute to increased expression of multiple RGS transcripts during neuronal differentiation.

\section{Materials and Methods}

\section{Cell Culture}

Human neural progenitor cells (hNPs) derived from WA09 human embryonic stem cells (Aruna Biomedical, Athens, Ga., USA) were grown on cell culture dishes precoated with Matrigel (BD Bioscience, San Jose, Calif., USA) in Neurobasal Medium (Gibco, Carlsbad, Calif., USA) as described [10]. The hNPs were grown in $\mathrm{AB2}^{\mathrm{TM}}$ Basal Neural Medium supplemented with 2\% ANS $^{\mathrm{TM}}$ Neural Medium Supplement (Aruna Biomedical, Athens, Ga., USA), 1\% L-glutamine, 1\% penicillin/streptomycin, $20 \mathrm{ng} / \mathrm{ml}$ basic fibroblast growth factor (bFGF) (R\&D Systems, Minneapolis, Minn., USA) and $10 \mathrm{ng} / \mathrm{ml}$ leukemia inhibitory factor (EMD Millipore, Billerica, Mass., USA). hNPs were differentiated for 2 weeks (denoted hN2) via bFGF withdrawal. Cells were treated with $5 \mu \mathrm{m}$ of 5-Aza-2'-deoxycytidine (Sigma Aldrich) for 5 days or $500 \mathrm{~nm}$ trichostatin A (TSA; Sigma Aldrich) for 36 h. Human SK-N-BE(2) neuroblastoma cells (ATCC, Manassas, Va., USA) were grown in a 1:1 mixture of Eagle's minimum essential medium and F12 medium with 10\% fetal bovine serum. Both cell lines were incubated at $37^{\circ} \mathrm{C}$ in $95 \%$ humidity and $5 \% \mathrm{CO}_{2}$. All cell lines were plated at a concentration of $1,000,000$ cells $/ \mathrm{ml}$ in a $100-\mathrm{mm}$ tissue culture plate. 
Quantitative Real-Time PCR

After drug treatment and/or differentiation, media was aspirated and RNA isolation was performed using Trizol reagent (Invitrogen) according to the manufacturer's recommended protocol. DNA was synthesized from $2 \mu \mathrm{g}$ of total RNA using the High Capacity Reverse Transcriptase cDNA kit (Applied Biosystems). Quantitative real-time PCR was performed using the Superscript III kit for RT-PCR (Invitrogen), and the Power SYBR Green reagent (Applied Biosystems) was used to define threshold cycle (CT) values. Transcript expression was assessed using a 7900HT Real-Time PCR System (Applied Biosystems; Life Technologies). Reactions were normalized using the housekeeping genes glyceraldehyde 3-phosphate dehydrogenase (GAPDH) and $\beta$-actin (ACTB), and calculations were performed according to the $2^{-\triangle A C T}$ method [11]. Primers were based on algorithm-generated sequences from Primer Bank [12].

Promoter Analysis

RGS promoter sequences were obtained from the National Center for Biotechnology Information (NCBI) database, using the GENE tool and sequence viewer. Genomic DNA sequences 1,000 bp upstream and $500 \mathrm{bp}$ downstream of the transcriptional start sites were used, and transcriptional start sites were determined based on mRNA Refseq files (NCBI) [13].

\section{Results and Discussion}

We explored changes in RGS transcript expression during in vitro differentiation of a well-characterized human neural progenitor cell model, namely hNP (Millipore) [14, 15]. hNP cells were differentiated for 2 weeks via bFGF withdrawal, resulting in differentiated hN2 cells. As previously reported, hN2 cells displayed high expression of the neuronal markers MAP2 and Tuj, reduced expression of the progenitor marker nestin, and robust neurite extension (data not shown). RNA was isolated from the differentiated hN2 cells and in parallel from proliferating undifferentiated hNP cells, and the expression of a panel of RGS transcripts expressed in CNS tissues was compared in the two cell populations (table 1). As shown in figure 1, the transcripts RGS6, RGS7, and RGS11 were strongly upregulated (10-20 fold) in hN2 cells. RGS4 and RGS5 were upregulated to a lesser extent, approximately six and four times higher in hN2 cells versus progenitor cells, respectively. Similarly, RGS9 showed a small but consistent trend of increased expression following differentiation, although not statistically significant. In contrast, two RGS transcripts were suppressed following neuronal differentiation; RGS8 and RGS14 each showed approximately 75\% lower expression in hN2 cells (fig. 1b). RGS2, RGS10, RGS17, RGS12, and RGS20 showed no consistent or significant change in expression between progenitors and differentiated neurons (fig. 1c).

We noted that the three most highly upregulated RGS transcripts (RGS6, RGS7, RGS11) during neuronal differentiation were members of the R7 subfamily, and RGS9, the fourth member of this family, was also trending toward upregulation. R7 family proteins are stabilized by association with the binding partners R7 family-binding protein (R7BP), RGS9 anchoring-protein (R9AP, also known as RGS9-binding protein, RGS9BP), and G $\beta 5$. Thus, we predicted simultaneous upregulation of their expression as well. Indeed, transcript levels of R7BP and R9AP were significantly higher in hN2 cells versus progenitor cells (fig. 1d). The G $\beta 5$ transcript level was not significantly higher in hN2 versus hNP, but was high in both populations (table 1). Therefore, transcripts encoding R7 proteins and the requisite-binding partners R7BP and R9AP are upregulated during neuronal differentiation.

Epigenetic silencing of cell fate-specific genes is an established mechanism of stem cell maintenance [16]. Further, others and we have demonstrated epigenetic regulation of RGS transcript expression in cancer cells via DNMT and HDAC activity $[8,17]$. We predicted that the observed increase in expression of multiple RGS transcripts might reflect release of epigenetic silencing by these mechanisms in the progenitor cells. To test this prediction, we 
Table 1. Summary of the transcriptional regulation of RGS genes in neural progenitors

\begin{tabular}{|c|c|c|c|c|c|c|c|c|c|}
\hline \multirow[t]{2}{*}{ RGS } & \multirow{2}{*}{$\begin{array}{l}\text { CT in NPs } \\
\text { (SD) }\end{array}$} & \multicolumn{2}{|l|}{ Primers } & \multirow{2}{*}{$\begin{array}{l}\Delta, \\
\text { NP-N2 }\end{array}$} & \multirow{2}{*}{$\begin{array}{l}\text { Chromosome (strand): } \\
\text { transcription start site }\end{array}$} & \multirow{2}{*}{$\begin{array}{l}\text { CpG } \\
\text { island }\end{array}$} & \multirow{2}{*}{$\begin{array}{l}\Delta, \\
\text { TSA } \\
\text { hNP }\end{array}$} & \multirow{2}{*}{$\begin{array}{l}\Delta, \\
5-\text { Aza }\end{array}$} & \multirow{2}{*}{$\begin{array}{l}\Delta, 5-A z a \\
\text { SK-N-BE }\end{array}$} \\
\hline & & forward & reverse & & & & & & \\
\hline RGS2 & $24.37(1.73)$ & $\begin{array}{l}\text { AAG ATT GGA AGA CCC } \\
\text { GTT TGA G }\end{array}$ & $\begin{array}{l}\text { GCA AGA CCA TAT TTG } \\
\text { CTG GCT }\end{array}$ & - & $1 q 31(+): 192,778,169$ & + & - & $\uparrow$ & $\uparrow$ \\
\hline RGS4 & $30.69(0.195)$ & $\begin{array}{l}\text { GGC TTC TTG CTT GAG } \\
\text { GAG TG }\end{array}$ & $\begin{array}{l}\text { TCC AGT GAT TCA GCC CAT } \\
\text { TTC }\end{array}$ & $\uparrow$ & 1q23.3, (+): 163,038,396 & - & $\uparrow$ (n.s.) & $\uparrow$ & - \\
\hline RGS5 & $23.48(1.61)$ & $\begin{array}{l}\text { CCC ACT CAT GCC TGG } \\
\text { AAA GG }\end{array}$ & $\begin{array}{l}\text { CTT GGC TGG TTT CTC TGG } \\
\text { CT }\end{array}$ & $\uparrow$ & 1q23.1, (-): $-163,172,963$ & - & $\downarrow$ & $\uparrow$ & $\uparrow$ \\
\hline RGS6 & $28.43(0.932)$ & $\begin{array}{l}\text { GCA GAA AAC TTA GCA } \\
\text { AGA CTC CA }\end{array}$ & $\begin{array}{l}\text { GAC ATC CCA AAA GGC } \\
\text { TCG TTC }\end{array}$ & $\uparrow$ & $14 q 24.3,(+): 72,399,786$ & + & - & $\uparrow$ & $\uparrow$ \\
\hline RGS7 & $30.65(2.62)$ & $\begin{array}{l}\text { AGG CGC TCC ATT TGG } \\
\text { GAA C }\end{array}$ & $\begin{array}{l}\text { TCC TTG AGT GTG AGG } \\
\text { ACA TGA }\end{array}$ & $\uparrow$ & 1q43 (-): $-241,520,478$ & + & - & $\uparrow($ n.s.) & - \\
\hline RGS8 & $27.80(2.70)$ & $\begin{array}{l}\text { TGG AAC ACC TTA ACC } \\
\text { CGA AGC }\end{array}$ & $\begin{array}{l}\text { CAT CCC AGT CGA GTC CTC } \\
\text { A }\end{array}$ & $\downarrow$ & 1q25 (-): $-182,642,067$ & - & - & $\uparrow$ & $\uparrow$ \\
\hline RGS9L & $27.81(0.922)$ & $\begin{array}{l}\text { CAC ACT TGC TCG AGA } \\
\text { ACC AA }\end{array}$ & $\begin{array}{l}\text { CAG CAG GGA AAG TCT } \\
\text { TCT GG }\end{array}$ & $\uparrow($ n.s.) & $17 q 24(+): 63,133,456$ & + & - & $\uparrow$ & - \\
\hline RGS10 & $26.46(1.57)$ & $\begin{array}{l}\text { GCT GGA CAG AAA GGT } \\
\text { CAT GTA GA }\end{array}$ & $\begin{array}{l}\text { GAC CCA GAA GGC GTG } \\
\text { AAA AGA }\end{array}$ & - & 10q25 (-): $-121,302,222$ & + & $\uparrow($ n.s.) & $\uparrow$ & - \\
\hline RGS11 & $29.45(1.18)$ & $\begin{array}{l}\text { GAC CCC GTA CTT CTG } \\
\text { GAC AAG }\end{array}$ & $\begin{array}{l}\text { CCC GTT TTC GGA TGT TCT } \\
\text { TCT }\end{array}$ & $\uparrow$ & $16 p 13.3(-):-325,914$ & + & - & - & - \\
\hline RGS12 & $23.76(1.48)$ & $\begin{array}{l}\text { GGA CGA AGC AGA GGA } \\
\text { GTT TTT }\end{array}$ & $\begin{array}{l}\text { TGT GGA ACC AGG TAA } \\
\text { ACG }\end{array}$ & - & 4 p16.3 (+):3,315,874 & - & $\downarrow$ & - & - \\
\hline RGS14 & $27.18(1.24)$ & $\begin{array}{l}\text { CGC GGA AAA CGT GAC } \\
\text { TTT CTG }\end{array}$ & $\begin{array}{l}\text { CTG ACG GTC GAT GTT CAC } \\
\text { TGG }\end{array}$ & $\downarrow$ & $5 q 35.3(+): 176,784,844$ & - & - & $\uparrow$ & $\uparrow$ \\
\hline RGS17 & $26.34(1.53)$ & $\begin{array}{l}\text { CAG AGG AAG TCT TGT } \\
\text { CCT GGT }\end{array}$ & $\begin{array}{l}\text { CAA GCA AGC CAG AAA } \\
\text { AGT AGG T }\end{array}$ & - & $6 q 25.3(-):-153,452,389$ & + & - & - & - \\
\hline RGS20 & $26.75(0.367)$ & $\begin{array}{l}\text { GGG CTC CAG ATG GGA } \\
\text { TCA GA }\end{array}$ & $\begin{array}{l}\text { TGA GAC ACG AGC AGC } \\
\text { TAC AAC }\end{array}$ & - & $8 q 11.23(+): 54,764,368$ & - & $\downarrow$ & - & - \\
\hline R7BP & $35.24(3.62)$ & $\begin{array}{l}\text { CCT GGA CGA CTG CAA } \\
\text { GAT G }\end{array}$ & $\begin{array}{l}\text { ATG GCA GCC AAT TTT } \\
\text { TGG TGT }\end{array}$ & $\uparrow$ & $5 q 12.3(+): 63,801,774$ & + & $\uparrow$ (n.s.) & $\uparrow$ & $\uparrow$ \\
\hline R9AP & $31.30(1.88)$ & $\begin{array}{l}\text { GAG TGT CCC GAG AGC } \\
\text { AGT TC }\end{array}$ & $\begin{array}{l}\text { ACT GGA TCC AAG TCC } \\
\text { GTG AG }\end{array}$ & $\uparrow$ & $19 q 13.11(+): 33,166,313$ & + & $\uparrow($ n.s.) & $\uparrow$ & $\uparrow$ \\
\hline Gß5 & $23.63(1.13)$ & $\begin{array}{l}\text { CCT AGC CCC AGG ATT } \\
\text { ACA AGG }\end{array}$ & $\begin{array}{l}\text { ACT CAT CCG ATT TGG CTC } \\
\text { TTT C }\end{array}$ & - & 15q21.2(-): $-52,472,162$ & + & - & - & - \\
\hline DNMT1 & $21.36(2.88)$ & $\begin{array}{l}\text { AGG GAA GAC TCG ATC } \\
\text { CTC GTC }\end{array}$ & $\begin{array}{l}\text { GTG TGT AGC TTA GCA } \\
\text { GAC TGG }\end{array}$ & - & & & & & \\
\hline DNMT3b & $21.72(1.35)$ & $\begin{array}{l}\text { GTG CAT GGA CTG GTG } \\
\text { CAA AG }\end{array}$ & $\begin{array}{l}\text { CCG ATG GGGCAT AAG CAC } \\
\text { AT }\end{array}$ & $\downarrow$ & & & & & \\
\hline HDAC1 & $19.47(1.53)$ & $\begin{array}{l}\text { GGT CCA AAT GCA GGC } \\
\text { GAT TCC T }\end{array}$ & $\begin{array}{l}\text { TCG GAG AAC TCT TCC TCA } \\
\text { CAG G }\end{array}$ & $\downarrow$ & & & & & \\
\hline
\end{tabular}

compared expression of the major enzyme isoforms responsible for DNA methylation (DNMT1 and DNMT3) and histone deacetylation (HDAC1) in neural progenitors and differentiated neurons. DNMT3 and HDAC1 were significantly decreased in hN2 versus hNP cells (fig. 2). This suggests that changes in expression of enzymes that modify DNA methylation and histone acetylation may contribute to changes in RGS gene expression during neuronal differentiation. To more directly address the role of DNMT and HDAC enzymes on RGS transcript expression in neural progenitors, we determined the effect of pharmacological inhibitors of DNMT and HDAC enzymes on RGS transcript expression in hNP cells. We first treated hNP cells with $500 \mathrm{~nm}$ of the broad-spectrum HDAC inhibitor TSA for $36 \mathrm{~h}$ and determined the 


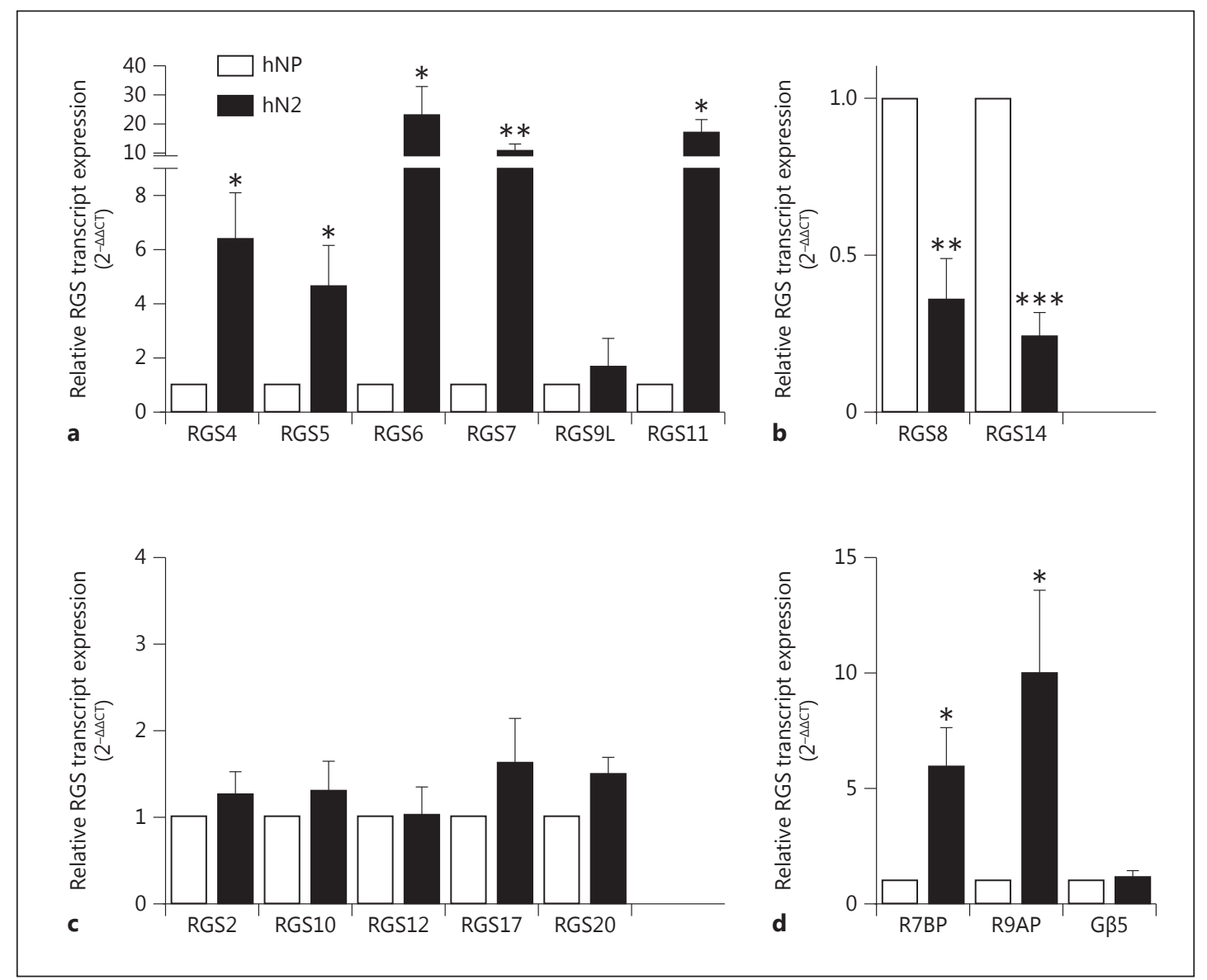

Fig. 1. Changes in RGS transcript expression during in vitro differentiation of hNP cells. hNP cells were differentiated via a 2-week bFGF withdrawal (hN2), and transcript expression was compared to that in undifferentiated hNP cells. Isolated total RNA was analyzed by qRT-PCR using primers specific for RGS transcripts, R7 family-binding protein transcripts and housekeeping genes. The graphs represent pooled data from three independent experiments. $2^{-\Delta \Delta C T}$ values were calculated using both GAPDH and actin control genes. a RGS transcripts upregulated during hN2 expression. b RGS transcripts downregulated during neuronal differentiation. c RGS transcripts unchanged during neuronal differentiation. d Expression of transcripts encoding R7 family-binding proteins. ${ }^{*} \mathrm{p}<0.05,{ }^{* *} \mathrm{p}<0.01,{ }^{* * *} \mathrm{p}<0.001$.

effect on RGS transcript expression. RGS7 was significantly upregulated in response to TSA treatment (fig. 3a), while RGS4, R7BP, and RGS10 were consistently higher in TSA treated cells, but due to variability in the magnitude of the change between independent experiments the change was not significant. Consistent with published observations, treatment of neural progenitor cells with TSA resulted in significant changes in cell morphology and reduced viability [18], and these effects may have contributed to the variability between independent experiments. Surprisingly, three RGS transcripts were strongly downregulated following TSA treatment in neural progenitors. The transcript levels of RGS5, RGS12, and RGS20 were reduced by $60-80 \%$ following HDAC inhibition (fig. $3 \mathrm{~b}$ ), while these transcripts were either unchanged or increased expression during neuronal differentiation. Thus, direct inhibition of HDAC activity did not recapitulate changes in RGS expression during differentiation, suggesting that reduced HDAC1 expression in neuronal differentiation is not directly responsible for the observed changes in RGS expression during differentiation. 
Fig. 2. Changes in expression of transcripts encoding major DNMT and HDAC enzymes during $\mathrm{hNP} \rightarrow \mathrm{hN} 2$ differentiation. The expression of epigenetic silencing enzymes reduced in neuronal differentiation. hNP cells were differentiated via a 2 -week bFGF withdrawal (hN2), and transcript expression was compared to that in undifferentiated hNP cells. Isolated total RNA was analyzed by qRT-PCR using primers specific for enzyme encoding transcripts and housekeeping genes. The graphs represent pooled data from two independent experiments. $2^{-\triangle \Delta C T}$ values were calculated using both GAPDH and actin control genes. ${ }^{* * *} \mathrm{p}<0.001$.

Tuggle et al:: Regulator of G Protein Signaling Transcript Expression in Human Neural Progenitor Differentiation: R7 Subfamily Regulation by DNA Methylation
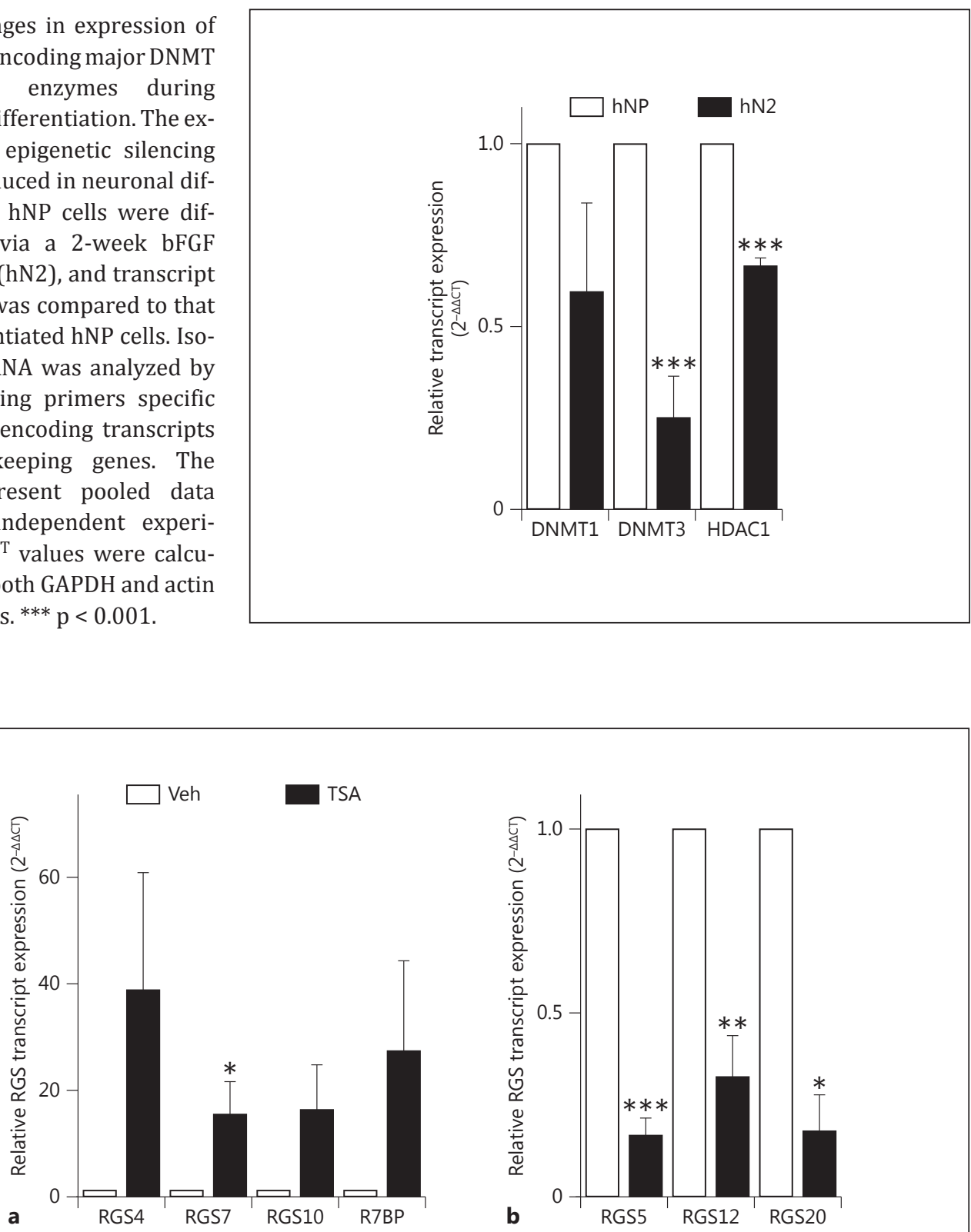

Fig. 3. Changes in RGS transcript expression following HDAC inhibition. hNP cells were treated with vehicle or $500 \mathrm{~nm}$ TSA for $36 \mathrm{~h}$, and transcript expression was determined as described in figure 1 and in the Methods section. a Upregulation of RGS and R7 family-binding protein transcripts following HDAC inhibition. b Downregulation of RGS and R7 family-binding protein transcripts following HDAC inhibition. * p $<0.05$, ${ }^{* *} \mathrm{p}<0.01,{ }^{* * *} \mathrm{p}<0.001$. Veh $=$ Vehicle.

To address the role of DNMT regulation of gene expression in neural progenitors, we similarly treated hNP cells with $5 \mu \mathrm{M}$ 5-Aza deoxycytidine (5-Aza), a broad-spectrum DNMT inhibitor, for 5 days. DNMT inhibition resulted in strong upregulation (10 fold or higher) of RGS4, RGS6, R7BP, RGS8, and R9AP (fig. 4). With the exception of RGS8, all of these transcripts were also upregulated during neuronal differentiation. Several additional RGS transcripts 
Tuggle et al:: Regulator of G Protein Signaling Transcript Expression in Human Neural

Progenitor Differentiation: R7 Subfamily Regulation by DNA Methylation

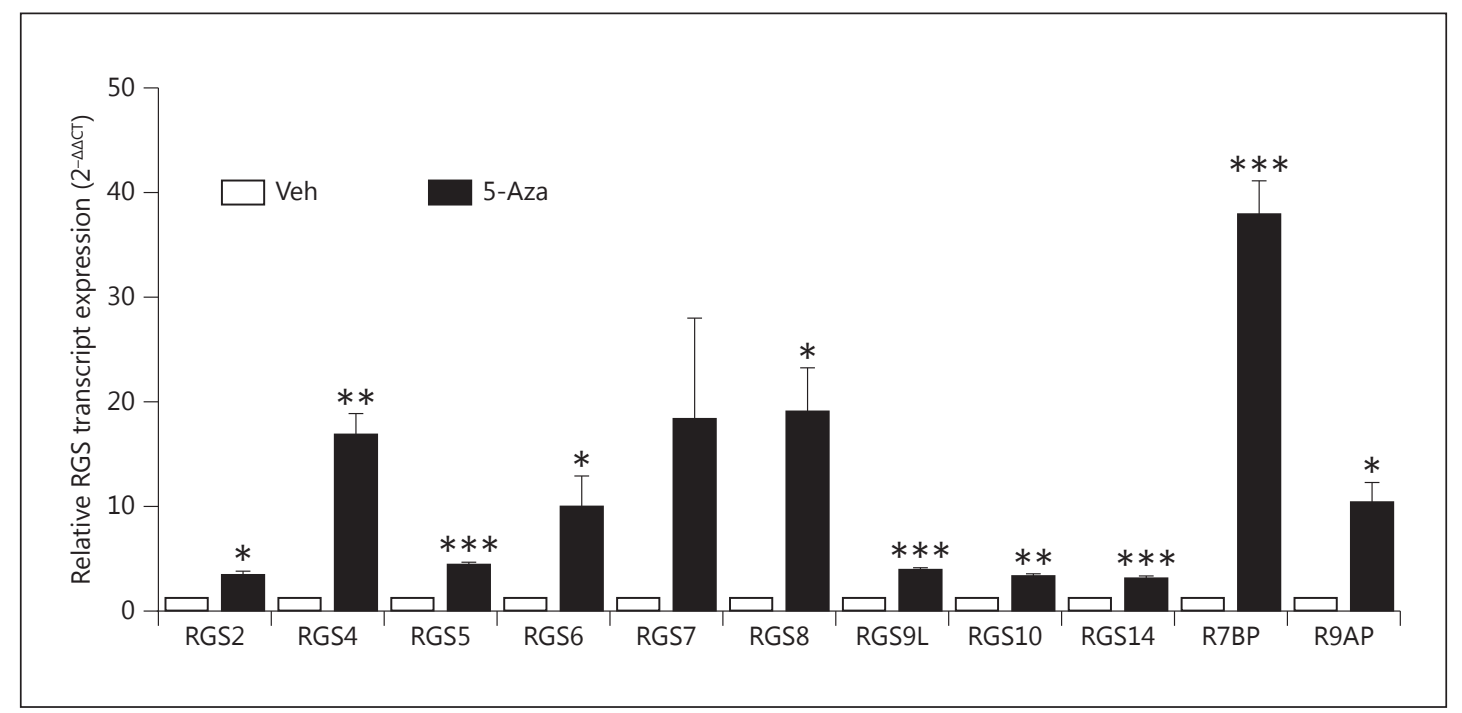

Fig. 4. Upregulation of RGS transcript expression by DNMT inhibition. hNP cells were treated with vehicle or 5 нм 5-Aza for 5 days, and transcript expression was determined as described in figure 1 and in the Methods section. ${ }^{*} \mathrm{p}<0.05,{ }^{* *} \mathrm{p}<0.01,{ }^{* * *} \mathrm{p}<0.001$. Veh $=$ Vehicle.

were significantly upregulated, although to a lesser degree following 5-Aza treatment: RGS2, RGS5, RGS9, RGS10, and RGS14. RGS7 was consistently upregulated with 5-Aza treatment, but there was high variability in the magnitude of change (between 2-40 fold in three independent experiments), so this effect was not statistically significant ( $p=0.15)$. RGS11, RGS12, RGS17, and RGS20 showed no change in expression following 5-Aza. Overall, seven of the nine RGS transcripts upregulated during neuronal differentiation were also upregulated following direct DNMT inhibition. Similarly, four of the six RGS transcripts that were unchanged during neuronal differentiation were also unchanged following DNMT inhibition. Thus, direct inhibition of DNMT enzymes recapitulated the regulation of most - but not all - RGS transcripts during neuronal differentiation. Together, these data suggest that the observed loss of DNMT expression during differentiation may contribute to upregulation of RGS4, RGS5, RGS6, RGS7, RGS9, R7BP and R9AP transcripts, while distinct mechanisms likely mediate the observed changes in RGS11, RGS14, and RGS8 during neuronal differentiation.

To determine if the effects of DNMT inhibition on RGS transcription are unique to neural progenitor cells, we also determined the effect of DNMT inhibition by 5-Aza in a neuronal cell model, namely SK-N-BE(2) human neuroblastoma cells. Of the 11 transcripts upregulated in response to 5-Aza in hNP cells, RGS2, RGS5, RGS6, RGS8, RGS14, R7BP, and R9AP were also upregulated in response to 5-Aza treatment in SK-N-BE cells, while RGS4, RGS7, RGS9 and RGS10 were not significantly upregulated (table 1). Thus, RGS transcripts may be more sensitive to regulation by inhibition of DNMT in hNP cells compared to SK-N-BE cells, likely reflecting the high basal DNMT expression levels in hNP cells. DNMT enzymes can directly modify the promoters of genes by methylating $\mathrm{CpG}$ dinucleotides, and genes with high concentrations of CpG nucleotides are often targets of DNMT regulation. To determine if RGS promoters are good candidates for direct regulation by DNA methylation, we also determined the GC content of RGS promoters. RGS2, RGS6, RGS7, RGS9 and RGS10, as well as genes encoding the R7 family-associated proteins R7BP and R9AP, contained regions of $>60 \% \mathrm{GC}$ content and high density of $\mathrm{CpG}$ dinucleotides in their proximal promoters, consistent with their upregulation upon pharmacological inhibition of DNMT (see suppl. material, www. 
karger.com/doi/10.1159/000362128). However, the presence of a proximal CpG island did not broadly correlate with the regulation of RGS expression by DNMT, consistent with growing evidence that regulation of gene expression by DNMT enzymes may occur well upstream of proximal promoters and in regions with lower CpG density $[19,20]$.

Our previous studies have shown differential regulation of GPCR expression upon neuronal differentiation [1]. The results of this study demonstrate dramatic upregulation of multiple RGS transcripts during in vitro differentiation of human neural progenitors, while RGS14 and RGS8 were strongly downregulated. These changes are predicted to have significant impact on the strength and selectivity of GPCR signaling during differentiation. GPCRs

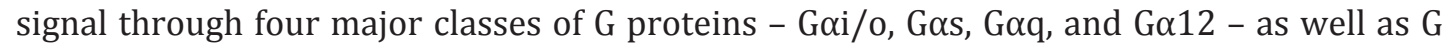
protein independent mechanisms. Notably, all RGS transcripts shown to be upregulated during neuronal differentiation in this study encode Gai/o subfamily GAPs, which may result in a significant shift in the balance of Gi/o signaling relative to these other pathways. Gai/o activity has been directly linked to neural progenitor proliferation [21] and neurogenesis [22], and enhanced Gi/o-targeted GAP activity likely directly impacts the function of these pathways in response to multiple Gi-coupled receptors. Further, in vitro differentiation of hNP cells in the presence of the Gi/o inhibitor pertussis toxin results in reduced cell survival and enhanced neuronal marker expression (data not shown). In contrast, differentiation of hNP cells in the presence of HDAC and DNMT inhibitors inhibits neuronal differentiation and promotes astrocytic differentiation [23]. Additional studies are needed to elucidate the direct functional impact of specific RGS proteins on specific GPCRs and G proteins in differentiation of neural progenitors and mature neurons.

The RGS transcripts that were most strongly upregulated encode members of the R7 subfamily of RGS proteins, and we also observed upregulation of transcripts encoding the R7 family-associated proteins R7BP and R9AP. Our results are consistent with a previous report of increased RGS9 expression during neural differentiation [24], and RGS6 has been reported to play a role in neuronal differentiation [25]. Further, R7 family members are critical regulators of neuronal function [26-28], and their increased expression may impact signaling by multiple GPCR-coupled neurotransmitters during neuronal differentiation. The promoters of all four members of the R7 subfamily and of both R7 associated proteins contain proximal CpG islands, and all except RGS11 are upregulated in hNP cells following direct DNMT inhibition. Thus, our studies establish DNMT activity as a potential regulator of R7 family transcription and suggest that the decrease in DNMT enzyme expression during neuronal differentiation contributes to the dramatic increase in R7 family expression via release of epigenetic suppression.

\section{Acknowledgements}

This work was supported by the UGA College of Pharmacy Dean's Research Endowment fund.

\section{References}

- 1 Callihan P, Mumaw J, Machacek DW, Stice SL, Hooks SB: Regulation of stem cell pluripotency and differentiation by G protein coupled receptors. Pharmacol Ther 2010;129:290-306.

- 2 Lefkowitz RJ: Seven transmembrane receptors: something old, something new. Acta Physiologica 2007;190: 9-19.

- 3 Siderovski DP, Hessel A, Chung S, Mak TW, Tyers M: A new family of regulators of G-protein-coupled receptors? Curr Biol 1996;6:211-212.

4 Rens-Domiano S, Hamm HE: Structural and functional relationships of heterotrimeric G-proteins. Faseb J 1995;9:1059-1066. 
Srinivasa SP, Watson N, Overton MC, Blumer KJ: Mechanism of RGS4, a GTPase-activating protein for G protein alpha subunits. J Biol Chem 1998;273:1529-1533.

- 6 Doze VA, Perez DM: GPCRs in stem cell function. Prog Mol Biol Transl Sci 2013;115:175-216.

7 Peng H, Kolb R, Kennedy JE, Zheng J: Differential expression of CXCL12 and CXCR4 during human fetal neural progenitor cell differentiation. J Neuroimmune Pharmacol 2007;2:251-258.

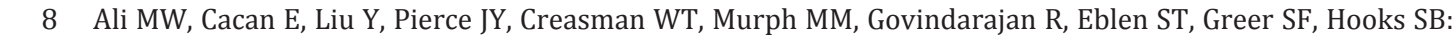
Transcriptional suppression, DNA methylation, and histone deacetylation of the regulator of G-protein signaling 10 (RGS10) gene in ovarian cancer cells. PloS One 2013;8:e60185.

- 9 Coskun V, Tsoa R, Sun YE: Epigenetic regulation of stem cells differentiating along the neural lineage. Curr Opin Neurobiol 2012;22:762-767.

10 Callihan P, Zitomer NC, Stoeling MV, Kennedy PC, Lynch KR, Riley RT, Hooks SB: Distinct generation, pharmacology, and distribution of sphingosine 1-phosphate and dihydrosphingosine 1-phosphate in human neural progenitor cells. Neuropharmacology 2012;62:988-996.

11 Livak KJ, Schmittgen TD: Analysis of relative gene expression data using real-time quantitative PCR and the 2(-Delta Delta C(T)) Method. Methods 2001;25:402-408.

12 Wang X, Spandidos A, Wang H, Seed B: PrimerBank: a PCR primer database for quantitative gene expression analysis, 2012 update. Nucleic Acids Res 2012;40:D1144-D1149.

13 Li LC, Dahiya R: Methprimer: designing primers for methylation PCRs. Bioinformatics 2002;18:1427-1431.

14 Hurst JH, Mumaw J, Machacek DW, Sturkie C, Callihan P, Stice SL, Hooks SB: Human neural progenitors express functional lysophospholipid receptors that regulate cell growth and morphology. BMC Neurosci 2008;9:118.

15 Dhara SK, Hasneen K, Machacek DW, Boyd NL, Rao RR, Stice SL: Human neural progenitor cells derived from embryonic stem cells in feeder-free cultures. Differentiation 2008;76:454-464.

16 Burney MJ, Johnston C, Wong KY, Teng SW, Beglopoulos V, Stanton LW, Williams BP, Bithell A, Buckley NJ: An epigenetic signature of developmental potential in neural stem cells and early neurons. Stem Cells 2013;31: 1868-1880.

17 Wolff DW, Xie Y, Deng C, Gatalica Z, Yang M, Wang B, Wang J, Lin MF, Abel PW, Tu Y: Epigenetic repression of regulator of G-protein signaling 2 promotes androgen-independent prostate cancer cell growth. Int J Cancer 2011, Epub ahead of print.

18 Wang H, Cheng H, Wang K, Wen T: Different effects of histone deacetylase inhibitors nicotinamide and trichostatin A (TSA) in C17.2 neural stem cells. J Neural Transm 2012;119:1307-1315.

19 Ziller MJ, Gu H, Muller F, Donaghey J, Tsai LT, Kohlbacher O, De Jager PL, Rosen ED, Bennett DA, Bernstein BE, Gnirke A, Meissner A: Charting a dynamic DNA methylation landscape of the human genome. Nature 2013; 500:477-481.

-20 Ji H, Ehrlich LI, Seita J, Murakami P, Doi A, Lindau P, Lee H, Aryee MJ, Irizarry RA, Kim K, Rossi DJ, Inlay MA, Serwold T, Karsunky H, Ho L, Daley GQ, Weissman IL, Feinberg AP: Comprehensive methylome map of lineage commitment from haematopoietic progenitors. Nature 2010;467:338-342.

-21 Shinohara H, Udagawa J, Morishita R, Ueda H, Otani H, Semba R, Kato K, Asano T: Gi2 signaling enhances proliferation of neural progenitor cells in the developing brain. J Biol Chem 2004;279:41141-41148.

22 Bromberg KD, Iyengar R, He JC: Regulation of neurite outgrowth by G(i/o) signaling pathways. Front Biosci 2008;13:4544-4557.

-23 Majumder A, Dhara SK, Swetenburg R, Mithani M, Cao K, Medrzycki M, Fan Y, Stice SL: Inhibition of DNA methyltransferases and histone deacetylases induces astrocytic differentiation of neural progenitors. Stem Cell Res 2013;11:574-586.

-24 Sharma M, Celver J, Kovoor A: Regulator of G protein signaling 9-2 (RGS9-2) MRNA is up regulated during neuronal differentiation of mouse embryonic stem cells. Neurosci Lett 2011;502:123-128.

-25 Liu Z, Chatterjee TK, Fisher RA: RGS6 interacts with SCG10 and promotes neuronal differentiation. Role of the G gamma subunit-like (GGL) domain of RGS6. J Biol Chem 2002;277:37832-37839.

26 Papachatzaki MM, Antal Z, Terzi D, Szucs P, Zachariou V, Antal M: RGS9-2 modulates nociceptive behaviour and opioid-mediated synaptic transmission in the spinal dorsal horn. Neurosci Lett 2011;501:31-34.

-27 Maity B, Stewart A, Yang J, Loo L, Sheff D, Shepherd AJ, Mohapatra DP, Fisher RA: Regulator of G protein signaling 6 (RGS6) protein ensures coordination of motor movement by modulating GABAB receptor signaling. J Biol Chem 2012;287:4972-4981.

28 Fajardo-Serrano A, Wydeven N, Young D, Watanabe M, Shigemoto R, Martemyanov KA, Wickman K, Lujan R: Association of Rgs7/G $\beta 5$ complexes with Girk channels and GABAB receptors in hippocampal CA1 pyramidal neurons. Hippocampus 2013, Epub ahead of print. 